\title{
Physics and Rock'n'Roll : Expanding to New Audiences
}

\author{
Connie Potter, ${ }^{a, *}$ Chris Thomas ${ }^{b}$ and Roger Jones ${ }^{c}$ \\ ${ }^{a} C E R N$, \\ Esplanade des Particules, Geneva, Switzerland \\ ${ }^{b}$ Iowa State University, \\ Ames, IA 50011, USA \\ ${ }^{c}$ Department of Physics, Lancaster University, \\ Physics Avenue, Lancaster LAl 4YB, UK \\ E-mail: connie.potter@cern.ch, christopher.david.thomas@cern.ch, \\ roger.jones@cern.ch
}

\begin{abstract}
A team of CERN staff and associates has organised public engagement and education activities at a variety of non-scientific venues. The core team now brands itself the Big Bang Collective, and local partners are engaged in each case, bringing in local knowledge and expertise. The principle recurring festivals that have been targeted are the WOMAD Festival (Charlton Park, UK, since 2016), joined from 2019 by Roskilde (Dk), Colours of Ostrava (Cz) and Pohoda (Sk). The goal of this effort is to engage new audiences who normally would not be drawn to science festivals and to investigate our ability to communicate scientific messages to broad, diverse audiences. Most of these festivals aim to present the broader culture, rather than just music; but none have a specifically scientific theme. They attract differing demographics, requiring individual customisation of the programme. In each case, the audience is not attending for the science, and have different prior levels of engagement. The results have been impressive, with 'meaningful engagement' (i.e. interactions upwards of 15 minutes) with over 20,000 people in 2019. We describe the presentation material and format, the hands-on workshops, and other methods employed, as well as lessons learned on how to best optimise audience engagement in each case.
\end{abstract}

40th International Conference on High Energy physics - ICHEP2020

July 28 - August 6, 2020

Prague, Czech Republic (virtual meeting)

\footnotetext{
${ }^{*}$ Speaker
} 


\section{Introduction}

Nearly everyone loves music and the arts; not always the same music, not always the same style of art, but we can safely say that most people are engaged with the arts and culture in some form. While science has its devotees amongst the public, it is too often seen as mysterious, unintelligible or complicated - in short, only for the "really smart people".

Using music and the broader arts as a channel for delivering basic messages of science to the general population has proven very successful in two ways. The Special Guest Programme invites a small number of famous musicians and other artists for private visits around CERN. The Festival Programme, now in its 5th year, actually does perform outreach: rather than hope the public will find a science event interesting, it goes out to where the 'unengaged' public can be found, at music and cultural festivals around the world and delivers the news about science to their doorstep. Both Programmes have a proven track record of reaching people of all ages and backgrounds. Much has been learned during these past 5 years since both programmes began, and we are taking those lessons going forward, expanding the reach and improving the experience for all.

\section{The Special Guest Programme}

While CERN has always welcomed VIPs for visits, these are generally Protocol visitors coming from Government bodies or major companies and are an everyday essential part of the life of a large international Organisation. With the construction of the LHC, the start-up of the big experiments and the discovery of the Higgs boson, CERN's name and work became known to a wider audience than usual. As a result it is not unusual to find a well-known non-scientist who, upon hearing the name CERN, displays interest to learn more about the work going on there. The Special Guest Programme has capitalised on this interest by inviting a limited number of famous, mainly musical, artists who happen to be performing at one of the local large music festivals in the local area, such as the Paléo Festival or the Montreux Jazz Festival, for a private and informal visit.

\subsection{The artists, the visit}

These artists often find themselves in the Geneva/Lausanne area for a couple of days and usually readily accept the invitation for a visit. Often, they ask to bring family and/or crew as well. They are given a tour around some key sites, such as one of the LHC underground experiments, the AntiMatter Factory, the Computer Centre (always of great interest, especially to the crew), with guides being specially chosen for each location. In these cases, it is essential to have guides who can explain in simple terms the physics at each point and answer any questions easily, without being "starstruck".

\subsection{The outcome}

First and foremost, we strive for a great post by the artist on their social media platform(s), and usually we have been very successful. On occasion, we have obtained interviews on site with the artists that we can share on CERN's platforms, that have been picked up by mainstream outlets. Throughout the time, sometime many hours, spent with these artists on a visit, we can start to gauge the real level of interest the artist may have in the science. Interestingly, we have seen that 


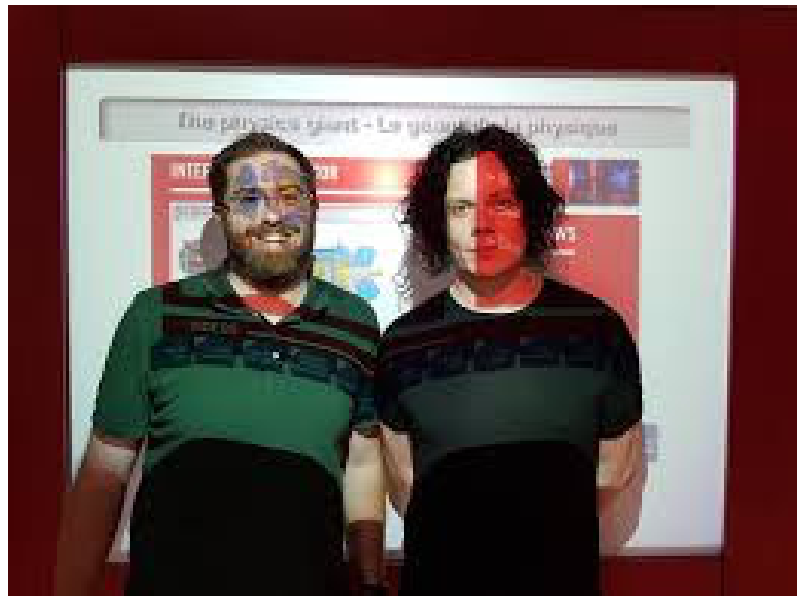

Figure 1: ATLAS guide Chris Martin welcomes musician Jack White

several very high profile artists have an impressively comprehensive knowledge and understanding of physics. With some artists we have seen a natural affinity with the team and the guides and that has resulted in a relationship that continues after the visit. Consequently, when a specific event or announcement that could benefit from a high-profile individual's involvement has arisen, we have been able to contact one of these artists and they have been happy to collaborate.

\section{The Festival Programme}

Finding science on the programme at a music or wider cultural festival is not common. Indeed, prior to 2015 it was almost unthinkable. That changed in 2015, with the first Physics Pavilion at the WOMAD festival in the UK. The Programme has grown, with WOMAD's Physics Pavilion being joined by three others in Slovakia, Denmark and the Czech Republic in 2019. The mixture of talks, workshops and hands-on science activities works well in these settings, although attention has to be paid to the location, infrastructure and the demographic of each festival.

\subsection{WOMAD}

Our first toe in the water of music festivals was in 2015 in the UK. Our original partners of the Institute of Physics (IoP) and Lancaster University, remain today. Starting out with one large Pavilion provided by the festival in which the whole programme was run, the offering grew, at the request of the Festival, to three main spaces : one where one could see talks and shows, one offering workshops and the last one a drop-in, hands-on space for quick activities. The festival-goers range from the very young to the very old, with a drop-off between the late teens and late twenties.

\subsection{Roskilde}

The Danish Roskilde Festival, one of the largest in the world, welcomes over 120'000 young people each year. The demographic is 16 to 28 year olds, intent on having a good time. It would be a challenge to attract these party-loving young people to a science space, but over many discussions with our collaborating team of young physicists from Niels Bohr Institute, the challenge was met. 


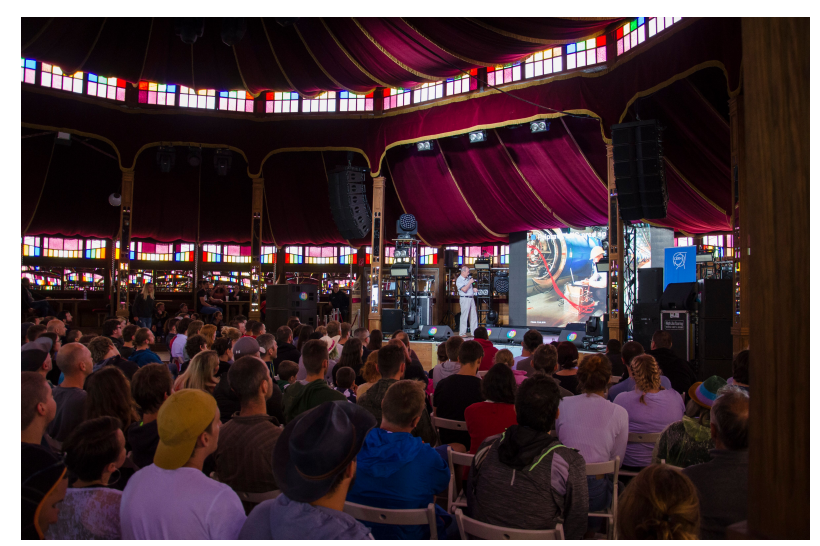

Figure 2: Physics stage at the Pohoda festival

While the concept - talks, shows and workshops - remained the same, the venue was arranged in a far more laid-back, lounge-type space, and the topics of the activities more tailored to the younger age group.

\subsection{Ostrava}

The Colours of Ostrava Festival in the Czech Republic, contains a 'sub-festival' - The Melting Pot - consisting solely of daily talks and shows on a variety of stages running in parallel with the musical offering. Within the old iron works venue of the festival, thanks to the contacts of the terrific local team from Charles University, we were able to take over one building that had been transformed into a science museum, to run 'The Big Bang Stage' for the duration. Again the 'WOMAD' concept was used. It was very interesting to notice a cultural shift from the ready-foranything attitude of the WOMAD or Roskilde audience, to a more reserved, cerebral audience. The Stage was very successful, with just under 3900 visitors over 4 days.

\subsection{Pohoda}

The Pohoda Festival in Slovakia takes place in a old airfield. The CEO Michal Kaščák, who was approached by our collaborating team at Comenius University, enthusiastically welcomed a Science Pavilion at his festival for the first time. The Magical Science Pavilion played to full houses over two days, offering talks and shows and, in spite of some logistical challenges, some popular workshops.

\section{Covid-19}

By Spring of 2020, it became clear that no in-person festivals would be taking place that Summer. Nevertheless WOMAD provided its audience with WOMAD at Home, allowing us to offer the first virtual World of Physics. Alongside talks and a show, we were able to reach out to one of our Special Guest visitors, the legendary musician David Crosby, for an online 'in conversation with' Jeffrey Hangst, the spokesperson of the Alpha experiment at CERN's Antimatter Factory. 


\section{Impact and Feedback}

Feedback from both the Festival management teams and the general public has been overwhelmingly positive. All Festivals have asked for more of the Science Pavilion concept, pleased with the unusual, popular new addition to their offering. As to the general public, success has been measured both by attendance numbers and feedback forms. In one month, for the four festivals, just over 20 '000 people in total attended the Science Pavilion spaces, with the age range running from 5 to over 75. Negative feedback comments can be counted in single digits with the main point being the request for more space or more workshops. For recurrent events, there is a significant people returning to the science programming. A common theme of the feedback from all the festivals has been one of pleasant surprise at finding science at a cultural festival along with the unexpected opportunity to discover, or re-discover, the joys and fascination of physics. Many have said they did not like or understand science at school, but being in the relaxed atmosphere at a festival, with real scientists on hand to explain concepts in simple language, resulted in them returning many times over to the Science Pavilions. Additionally, parents have shared how they were unaware of their child's interest in physics or computing, and delighted in being able to share in this interest in a workshop or at a talk. Even the physicist teams themselves have found the events very rewarding, as a UCL physicist told the BBC's Martin Vennard [1] 'It's changed the way I teach and speak to students. I've been able to take more risks..'

\section{The Future}

As previously stated, all the Festivals from 2019 were hoping to welcome back the Science Pavilion concept in 2020. Equally, approaches have been received from physicists learning of the Pavilions and wanting to try it out at a large festival in their country, new countries for the Festival programme.

What 2021 will bring, in terms of travel, live entertainment and mass gatherings of people, remains to be seen. Regardless, the Science Pavilion concept and the Special Guest programme have proven their success and remain committed to hopefully soon bringing the worlds of music and science together for the enrichment and enlightenment of the general public again.

\section{References}

[1] M. Vennard, The festivals mixing music and science, Bbc.com, 2018.

https://www . bbc. co.uk/news/science-environment- 45284935. 